\title{
Brisk clinical response to erythrocytapheresis in a G6PD-deficient patient with rasburicase-induced methemoglobinemia
}

\author{
Correspondence \\ Laura Cooling MD, MS, 2F225 UH-Blood Bank, 1500 E Medical Cntr Drive, Ann Arbor, Michigan, United States. \\ Email: lcooling@med.umich.edu
}

\section{Dear Editor,}

We read with interest the recent report by Montgomery and Booth, who described a case of methemoglobinemia in a 50-year-old, G6PD-deficient African American man with newly diagnosed T-cell lymphoblastic leukemia being treated with rasburicase for tumor lysis syndrome. ${ }^{1}$ Due to ongoing hemolysis and refractory hypoxia, the authors performed a one blood volume erythrocytapheresis with a $45 \%$ decrease in methemoglobin (14.6\%-8\%). Surprisingly, the patient continued to be hypoxic with subjective dyspnea, bilateral pleural effusions, and mildly elevated methemoglobin levels (7.5-11\%) for $36 \mathrm{~h}$ post-exchange. We would like to share our experience in a nearly identical patient several years ago, in whom we observed an immediate improvement in symptoms following erythrocytapheresis.

The patient was a $64 \mathrm{~kg}, 15$-year-old African-American male with a 2-week history of fever, Bell's palsy, lymphadenopathy, nausea, and abdominal pain due to new T-cell lymphoblastic leukemia. His initial laboratories showed a mildly elevated WBC count $(11.6 \mathrm{~K} / \mu \mathrm{L}$, range $13.7-17)$ with $40 \%$ circulating blasts, anemia (hemoglobin $11.4 \mathrm{~g} / \mathrm{dL}$ ), elevated lactate dehydrogenase ([LDH] 8375 IU/L, range 120-240 IU/L), hyperuricemia (29.5 $\mathrm{mg} / \mathrm{dL}$, range $3.5-7.8)$, and acute renal failure (creatinine $4.8 \mathrm{mg} / \mathrm{dL}$, range, $8-20$ ). While in the emergency room, he received $6 \mathrm{mg}$ rasburicase for tumor lysis syndrome. Within $3 \mathrm{~h}$ of receiving rasburicase, he became hypoxic with $\mathrm{O}_{2}$ saturation $70-80 \%$ despite escalating $\mathrm{O}_{2}$ supplementation, accompanied by falling hemoglobin and methemoglobinemia (16\%, range $0-1.5 \%)$. The patient was transfused 1 unit RBC and given a $25 \%$ test dose of methylene blue with no clinical improvement, worsening anemia, tachypnea (21-27 breaths/minute), and ongoing methemoglobinemia. Within $12 \mathrm{~h}$ of admission, the patient required intubation with $\mathrm{O}_{2}$ saturations $=60 \%$ on $100 \%$ $\mathrm{FiO}_{2}$, methemoglobin $=23 \%$, lactate $=5 \mathrm{mmol} / \mathrm{L}$ (range, 0.4-2.2), hemoglobin $=7.9 \mathrm{~g} / \mathrm{dL}, \mathrm{LDH}=12,699 \mathrm{IU} / \mathrm{L}$, and acidosis $(\mathrm{pH}=7.2)$. The patient subsequently underwent emergent erythrocytapheresis for methemoglobinemia and presumed G6PD-deficiency. The procedure was performed on a COBE Spectra at a whole blood: anticoagulant ratio of $7: 1,30 \%$ fraction cell remaining, an end hematocrit of $30 \%$, and 8 units group O RBC $(2693 \mathrm{~mL})$ for replacement. The patient had a brisk clinical response to erythrocytapheresis with $\mathrm{O}_{2}$ saturations $>90 \%$ by the end of the procedure. $\mathrm{He}$ was extubated approximately $4 \mathrm{~h}$ post-procedure with a methemoglobin $=5 \%$ and $\mathrm{O}_{2}$ saturation $=95 \%$ on $2 \mathrm{~L}$ supplemental oxygen. By day 3, the patient had normal $\mathrm{O}_{2}$ saturation on room air and a methemoglobin $=2.3 \%$. Subsequent testing confirmed that the patient was G6PD-deficient.

This is the fifth report of refractory methemoglobinemia treated by either whole-blood exchange or erythrocytapheresis, ${ }^{1-4}$ and the third case following rasburicase administration in G6PD-deficient patients. ${ }^{1,2}$ Like carbon monoxide poisoning, methemoglobinemia causes a left-shift in the $\mathrm{O}_{2}$ dissociation curve, leading to a progressive and refractory hypoxia that is exacerbated and amplified in the setting of anemia. ${ }^{5}$ Patients with symptomatic methemoglobinemia are typically treated with supplemental oxygen, RBC transfusion, and methylene blue, which helps restore glutathione levels. In G6PDdeficient patients, however, methylene blue can independently precipitate hemolysis and methemoglobinemia. This case shows a prompt improvement in oxygenation with erythrocytapheresis in the setting of methemoglobinemia and G6PDdeficiency, ${ }^{2,4}$ in whom methylene blue is contra-indicated.

Laura Cooling

Department of Pathology, University of Michigan Ann Arbor, Michigan

\section{REFERENCES}

[1] Montgomery KW, Booth GS. A perfect storm: tumor lysis syndrome with rasburicase-induced methemoglobinemia. J Clin Apher. 2017;32:62-63.

[2] Bhat P, Sisler I, Collier AB. Exchange transfusion as treatment for rasburicase-induced methemoglobinemia in a glucose-6-phoshate dehydrogenase deficient patient. Pediatr Blood Cancer. 2008;51: 568. 
\begin{tabular}{l|l|l|}
${ }^{600}$ & WI LEY & $\begin{array}{c}\text { Journal of } \\
\text { Clinical Apheresis ... ...SFA }\end{array}$ \\
\hline
\end{tabular}

[3] Golden PJ, Weinstein R. Treatment of high-risk, refractory acquired methemoglobinemia with automated red blood cell exchange. J Clin Apher. 1998;13:28-31.

[4] Dasararaju R, Adamski J. Transfusion medicine illustrated: an unusual case of near-fatal hemolytic anemia treated with erthryo- cytapheresis and therapeutic plasma exchange. Transfusion. 2015; 475-444.

[5] Wright RO, Lewander WJ, Woolf AD. Methemoglobinemia: etiology, pharmacology and clinical management. Ann Emerg Med. 1999;34:646-656. 